\title{
Sentinel node micrometastasis in breast carcinoma may not be an indication for complete axillary dissection
}

\author{
Heather Rutledge ${ }^{1,2}$, Joseph Davis ${ }^{1}$, Ronald Chiu ${ }^{1}$, Michael Cibull ${ }^{1}$, Yolanda Brill ${ }^{1}$, \\ Patrick McGrath ${ }^{1}$ and Luis Samayoa ${ }^{1,2}$ \\ ${ }^{1}$ Department of Pathology, University of Kentucky, Lexington, KY, USA and ${ }^{2}$ Veterans Administration Medical \\ Center, Lexington, KY, USA
}

\begin{abstract}
The decision whether to proceed with complete axillary node dissection based on sentinel node status is clear for patients with negative or macrometastatic disease. However, the course of action based on sentinel node micrometastasis remains controversial. We reviewed 358 cases from 6/1999 to $7 / 2003$. All sentinel nodes were evaluated at three levels by frozen section, touch preparation, and scrape preparation. Micrometastasis was defined as tumor deposits between 0.2 and $2 \mathrm{~mm}$. Size, grade, and lymphvascular invasion of the primary tumor, as well as number, status, size of metastatic disease, and presence of extranodal capsular extension of sentinel and nonsentinel nodes were recorded. Of the 358 cases, 89 had positive sentinel nodes, 29 of which represented micrometastases. Only one $(3 \%)$ of the 29 cases contained a nonsentinel node with macrometastasis. In 60 of the 89 cases sentinel nodes contained macrometastases. Of these, 38 cases (63\%) had metastatic tumor in nonsentinel nodes. Intraoperative consult was performed in $\mathbf{5 3}$ of the 89 cases with positive sentinel nodes. Only 1 of the $19(5 \%)$ intraoperative consult cases with micrometastatic sentinel nodes had positive nonsentinel nodes, while 21 of $34(62 \%)$ of macrometastatic sentinel nodes at intraoperative consult had tumor in nonsentinel nodes. No single variable studied discriminated between micro- vs macrometastatic disease. At intraoperative consult, macrometastatic disease was present in all three diagnostic preparations, while diagnostic material in micrometastatic sentinel nodes was usually present in only one modality. This analysis suggests that the risk of finding tumor in nonsentinel nodes differs significantly between cases with micro (3\%)- vs macro $(63 \%)$-metastatic disease in sentinel nodes. This holds true for cases assessed by intraoperative consult. Considering the known morbidity of complete axillary dissection, assessments of risk vs benefit of undertaking this procedure should be performed on a case-by-case basis in patients with sentinel node micrometastases.

Modern Pathology (2005) 18, 762-768, advance online publication, 11 March 2005; doi:10.1038/modpathol.3800394
\end{abstract}

Keywords: axillary node dissection; breast cancer; intraoperative consult; macrometastasis; micrometastasis; nonsentinel node; sentinel node

Sentinel node mapping for patients with breast cancer and clinically negative axilla has become the standard of care in many cancer centers. While it is well documented that this technique accurately predicts axillary node status in over $90 \%$ of the cases,${ }^{1-8}$ there are many relevant clinical decisions and surgical practices that have not been completely standardized. These include: (a) immediate complete axillary dissection based on sentinel node

Correspondence: Dr H Rutledge, MD, Department of Pathology, University of Kentucky, Suite MS 117, 800 Rose Street, Lexington, KY 40536-0001, USA.

E-mail: hlr1998@aol.com

Received 8 October 2004; revised 7 January 2005; accepted 8 January 2005; published online 11 March 2005 status at intraoperative consult vs complete axillary dissection as part of a second surgical procedure; (b) clinical value of complete axillary dissection following sentinel node micrometastasis; ${ }^{9-11}$ (c) clinical significance of tumor deposits less than $0.2 \mathrm{~mm}$ in size, detected either by hematoxylin and eosin (H\&E), immunohistochemistry, or cytology alone; ${ }^{12,13}$ (d) the best intraoperative consult detection method for metastatic disease (frozen section $v s$ cytology); ${ }^{14-18}$ (e) the definition of sentinel node micrometastatic disease at intraoperative consult; and (f) when to stop evaluating sentinel nodes in the presence of possible micrometastasis at intraoperative consult. ${ }^{9,10,19,20}$ Until the results from larger prospective studies such as NSABP-B32 and ACOS-OG-ZOO-11 become available, the answers to 
most of these clinical questions will remain controversial.

In this retrospective study, we address the predictive value of sentinel node micrometastasis in terms of probability of identifying metastatic disease in other lymph nodes submitted as additional sentinel nodes and/or nonsentinel nodes. We specifically focus on the issue of diagnosing micrometastatic disease at intraoperative consult and assessing the value of immediate complete axillary dissection if micrometastatic disease is found.

\section{Materials and methods}

We retrospectively reviewed and subclassified the outcomes of 358 sentinel node procedures performed at a single institution from 7/1999 to 6/ 2003 according to sentinel node and nonsentinel node status: Group $\mathrm{I}=(-)$ sentinel nodes, $(-)$ nonsentinel nodes; Group II $=(-)$ sentinel nodes with no nonsentinel nodes; Group $\mathrm{III}=(+)$ sentinel nodes, $(-)$ nonsentinel nodes; Group $\mathrm{IV}=(+)$ sentinel nodes, $(+)$ nonsentinel nodes and Group $\mathrm{V}=(-)$ sentinel nodes, $(+)$ nonsentinel nodes (Figure 1). Subsequently, each group was analyzed for number of sentinel nodes and nonsentinel nodes involved by tumor, size of metastatic disease, primary tumor grade, primary tumor size, presence of lymphvascular invasion, and extracapsular nodal extension. To evaluate the predictive value of sentinel node micrometastatic disease in terms of other sentinel node and nonsentinel node status, only the cases having at least one positive sentinel node (Groups III and IV), regardless of metastatic deposit size (Figures 2 and 3 ) and more than 10 nonsentinel nodes were evaluated.

\section{Definition of Sentinel Node}

In our institution, sentinel nodes are defined as: (a) any clinically suspicious lymph node at the time of

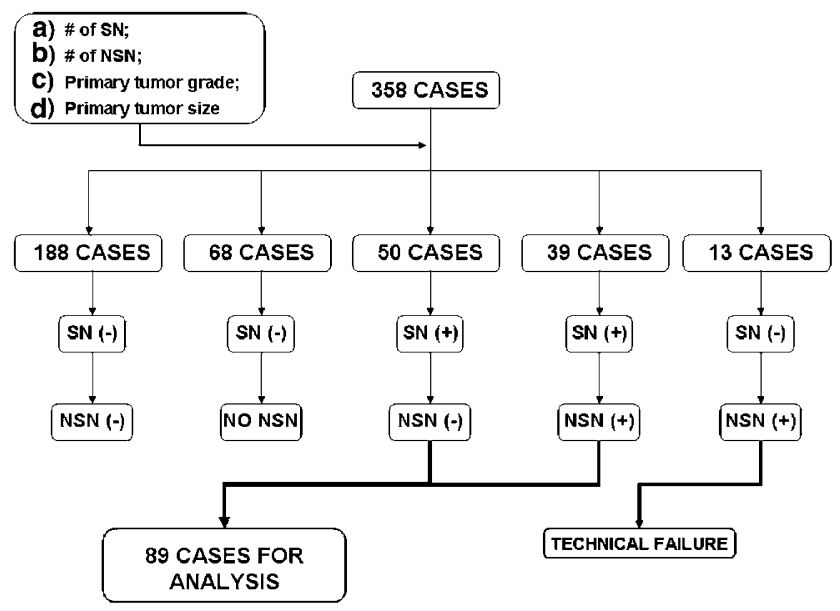

Figure 1 Distribution of 358 cases according to sentinel node status.

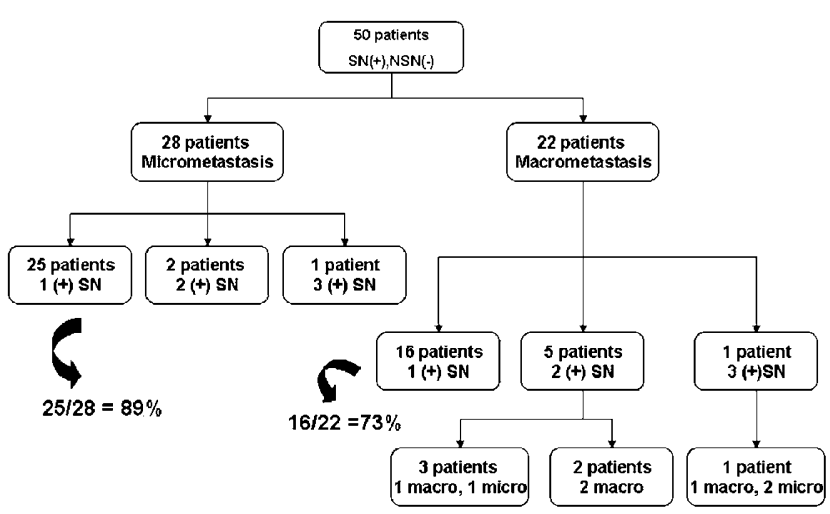

Figure 2 Single node involvement in cases with sentinel node $(+)$; nonsentinel node (-) micrometastatic disease vs multiple node involvement in cases with sentinel node $(+)$ macrometastatic disease.

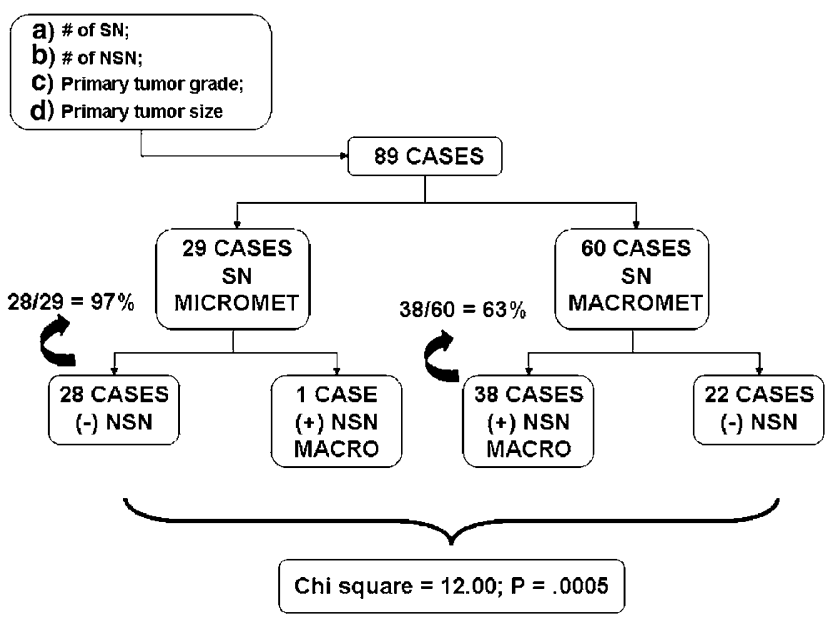

Figure 3 Nonsentinel node positivity (micro- or macrometastases) is significantly lower in patients with sentinel node micrometastasis than in patients with sentinel node macrometastatic disease (3 vs $63 \% ; P=0.005$ ).

surgery (regardless of radioactive count), (b) lymph nodes having the highest radioactive count, and (c) lymph nodes with radioactive counts at least $20 \%$ of the highest count lymph node. ${ }^{21}$

\section{Intraoperative Sentinel Node Evaluation}

Any specimen meeting criteria for sentinel node and submitted for intraoperative consult was transversely sectioned at $1.5 \mathrm{~mm}$ intervals along its long axis. The cut sections were grossly examined, with scrape preparations (scrape-prep) and touch preparations (touch-prep) performed for alcohol-fixed H\&E-stained slides. The specimens then were entirely frozen in multiple cassettes, depending on the size of the node and number of cut sections. Three levels (superficial, middle, and deep) were obtained from each block and stained by regular rapid H\&E method. When multiple sentinel nodes 
corresponding to a single case were submitted for intraoperative consult, the sentinel nodes were processed according to their radioactive counts, stopping at the detection of metastatic disease either by cytology (touch-prep and/or scrape-prep) and/or frozen section. Any sentinel node intraoperative consult with tumor detected either by cytology or frozen section led to a complete axillary dissection.

\section{Permanent Sentinel Node Histologic Procedure}

Sentinel nodes submitted for permanent processing were transversely sectioned along the long axis at $1.5 \mathrm{~mm}$ intervals. These sections were entirely submitted in cassettes and sent to histology, where three $\mathrm{H} \& \mathrm{E}$ slides representing the superficial, middle, and deep aspect of the node were obtained. Intervening sections between the different levels were retained on unstained slides for possible immunohistochemical analysis.

\section{Definition of Micrometastasis and Isolated Tumor Cells}

Between late 1999 and early 2003, no distinction was made between micrometastatic disease and isolated tumor cells. Metastatic tumor cells isolated or in clusters measuring $<0.2 \mathrm{~mm}$ either by H\&E or immunohistochemistry were regarded as micrometastatic disease. For the purpose of this study, all cases previously diagnosed as positive for micrometastasis were reclassified according to the current definition for breast micrometastatic disease provided by the AJCC 6th Edition Cancer Staging Manual, which defines micrometastasis as a tumor aggregate greater than 0.2 to $2.0 \mathrm{~mm}$ in size. ${ }^{22}$ Isolated tumor cells and tumor cell clusters measuring less than $0.2 \mathrm{~mm}$ were regarded as metastatic isolated tumor cells according to Singletary et al. ${ }^{23}$
Micrometastases and isolated tumor cell deposits were measured with the aid of a calibrated micrometer eye piece and ruler.

\section{Tumor Grade}

Tumors were graded as grade I, II, and III, according to the modified Bloom-Richardson histologic grading system, which is based on tubule formation, nuclear pleomorphism, and mitotic count/activity. ${ }^{24}$

\section{Results}

Based on sentinel node and nonsentinel node status, the 358 cases segregated into five groups (Figure 1): Group I: sentinel node (-); nonsentinel node $(-)=$ 188 cases (52\%); Group II: sentinel node (-) with no nonsentinel node $=68$ cases $(19 \%)$; Group III: sentinel node $(+)$; nonsentinel node $(-)=50$ cases (14\%); Group IV: sentinel node $(+)$; nonsentinel node $(+)=39$ cases $(11 \%)$ and Group V: sentinel node $(-)$; nonsentinel node $(+)=13$ cases $(4 \%)$. The histopathologic characteristics of these groups: tumor size, tumor grade, presence of lymphvascular invasion, size of sentinel node metastasis, and presence of extranodal metastatic extension are shown in Table 1. In this series, all these variables had statistically significant correlation with the presence of nodal disease. Tumor size was significantly different between node-negative and nodepositive cases, but did not predict micro- vs macrometastatic disease $(77 \%$ of the true nodenegative cases (sentinel node (-); nonsentinel node $(-))$ were T1 lesions).

Tumor grade was significantly different between the group of patients with node-negative disease and those with macrometastatic disease: $31 \%$ of grade I tumors in node-negative patients vs only $13 \%$ in patients with macrometastasis. In addition, grade III

Table 1 Histopathologic characteristics of 358 cases according to sentinel node status

\begin{tabular}{|c|c|c|c|c|c|c|c|c|}
\hline & \multirow{2}{*}{$\begin{array}{c}(-) S N \text { and } \\
(-) N S N \\
(\mathrm{n}=188)\end{array}$} & \multirow{2}{*}{$\begin{array}{c}(-) S N \\
\text { and NSN } \\
\text { not sampled } \\
(\mathrm{n}=68)\end{array}$} & \multicolumn{2}{|c|}{$(+) S N$ and $(-) N S N$} & \multicolumn{2}{|c|}{$(+) S N$ and $(+) N S N$} & \multirow{2}{*}{$\begin{array}{c}(-) S N \text { and } \\
(+) N S N \\
(\mathrm{n}=13)\end{array}$} & \multirow[t]{2}{*}{$\mathrm{P}$-value } \\
\hline & & & $\begin{array}{l}\text { Micro met } \\
(\mathrm{n}=29)\end{array}$ & $\begin{array}{c}\text { Macro met } \\
(\mathrm{n}=21)\end{array}$ & $\begin{array}{l}\text { Micro met } \\
\quad(\mathrm{n}=1)\end{array}$ & $\begin{array}{c}\text { Macro met } \\
(\mathrm{n}=38)\end{array}$ & & \\
\hline L V I $(n=54)$ & $13(7 \%)$ & $3(4 \%)$ & $11(38 \%)$ & $8(38 \%)$ & $0(0 \%)$ & $17(45 \%)$ & $2(15 \%)$ & $<0.001$ \\
\hline $\begin{array}{l}\text { Extra caps ext. } \\
\text { nodal mets }^{\text {a }} \\
(n=31)\end{array}$ & N/A & $\mathrm{N} / \mathrm{A}$ & $2(7 \%)$ & $8(38 \%)$ & $0(0 \%)$ & $17(45 \%)$ & $4(31 \%)$ & $<0.001$ \\
\hline \multicolumn{9}{|l|}{ Tumor grade } \\
\hline $\mathrm{I}(n=95)$ & $58(31 \%)$ & $21(31 \%)$ & $6(21 \%)$ & $2(9 \%)$ & $0(0 \%)$ & $5(13 \%)$ & $2(15 \%)$ & $<0.05$ \\
\hline $\mathrm{II}(n=165)$ & $85(45 \%)$ & $24(35 \%)$ & $19(65 \%)$ & $13(62 \%)$ & $1(100 \%)$ & $18(47 \%)$ & $6(46 \%)$ & \\
\hline III $(n=98)$ & $45(24 \%)$ & $23(34 \%)$ & $4(14 \%)$ & $6(29 \%)$ & $0(0 \%)$ & $15(40 \%)$ & $2(15 \%)$ & \\
\hline $\begin{array}{l}\text { Average tumor } \\
\text { size }(\mathrm{cm})\end{array}$ & 1.8 & 1.5 & \multicolumn{2}{|c|}{2.8} & \multicolumn{2}{|c|}{2.7} & 2.5 & $<0.001$ \\
\hline
\end{tabular}

LVI = Lymphvascular invasion; SN = sentinel node; NSN = nonsentinel nodes; micromet = micrometastasis; macromet = macrometastasis.

${ }^{\mathrm{a}}$ Extra nodal capsular extension. 
tumors were more common in cases with macrometastatic disease $(39 \%)$ than in patients with micrometastatic disease (14\%). Lymphvascular invasion was significantly different between nodenegative $(7 \%)$ vs node-positive patients for both, micrometastatic (38\%) and macrometastatic (42\%), but as in tumor size, lymphvascular invasion did not differ significantly between patients with micro- $v s$ macrometastatic disease. The presence of nodal extracapsular extension was significantly different between cases with micro- and macrometastatic disease, $7 \%$ for those with micrometastasis vs $42 \%$ for those with macrometastasis.

The majority of patients with sentinel node micrometastasis $(28 / 29=97 \%)$ had negative nonsentinel nodes, contrasting with patients with sentinel node macrometastasis in which only a third of the patients had negative nonsentinel nodes. Furthermore, the majority of patients with positive sentinel node (either micro or macro) and negative nonsentinel nodes had a single positive node $(41 / 50=82 \%)$ (Figure 2$)$. In this group, if the sentinel node was involved by micrometastatic disease, there was no other node (sentinel or nonsentinel) involved by tumor in 90\% (25/28) of the cases. On the other hand, when macrometastatic disease was identified, $27 \%(6 / 22)$ of the cases had other nodes involved by tumor.

To compare the chances of finding metastatic disease (micro or macro) in single vs multiple sentinel and nonsentinel lymph nodes once a diagnosis of micrometastasis is made either on permanent histology (Figure 3) or at intraoperative consult (Figure 4), groups III and IV were combined. The resulting 89 cases (sentinel node $(+)$ and nonsentinel node $(+$ or -$)$ ) included 53 cases with intraoperative consult.

A third of the cases from the permanent histology group $(29 / 89=33 \%)$ had sentinel node micrometastasis; $97 \%$ of these cases $(28 / 29=97 \%)$ were nonsentinel node $(-)$. Only $37 \%$ of the cases with sentinel node macrometastasis $(22 / 60=37 \%)$ were nonsentinel node $(-), \chi^{2}=12.00 ; P=0.0005$. Similar results were obtained when the intraoperative consult group was analyzed under the same parameters: $95 \%$ of the cases with sentinel node micrometastasis $(18 / 19=95 \%)$ were nonsentinel node (-) Vs only $38 \%$ of the cases with sentinel node macrometastasis $(13 / 34=38 \%)$ that had $(-)$ nonsentinel node, $\chi^{2}=6.27 ; P=0.012$.

The number of lymph nodes involved by metastatic disease (sentinel or nonsentinel) after a diagnosis of sentinel node metastasis, appeared related to the size of metastatic disease (macro- $v s$ micrometastatic) in the sentinel node (Figure 5). Of cases with micrometastasis, 86\% (25/29) had a single sentinel node involved by tumor, contrasting with the cases showing sentinel node macrometastatic disease, in which the majority of cases (44/ $60=73 \%$ ) had more than one node (sentinel node or nonsentinel node) involved by disease $\left(\chi^{2}=8.185\right.$; $P=0.0005$ ).

Of the original 50 cases with $(+)$ sentinel node and (-) nonsentinel node (Group III), 31 had intraoperative consult resulting in 18 cases with sentinel node micrometastasis and 13 cases with sentinel node macrometastasis (Figure 6). All cases with sentinel node macrometastasis at intraoperative consult had evidence of tumor cells in both the cytologic preparations (touch-prep and/or scrape-prep) and in the frozen section material. Of the 18 cases with final axillary node status positive for micrometastasis, four cases were missed at intraoperative consult, and in only five cases, tumor was present in both cytology and frozen section diagnostic preparations. For the remaining cases, tumor cells were detected by cytology alone in five cases, three cases had tumor cells in the frozen section only, and in one case only frozen section was performed.

At the time of intraoperative consult, there were cases in which the presence of metastatic disease was difficult to prove either on H\&E sections or

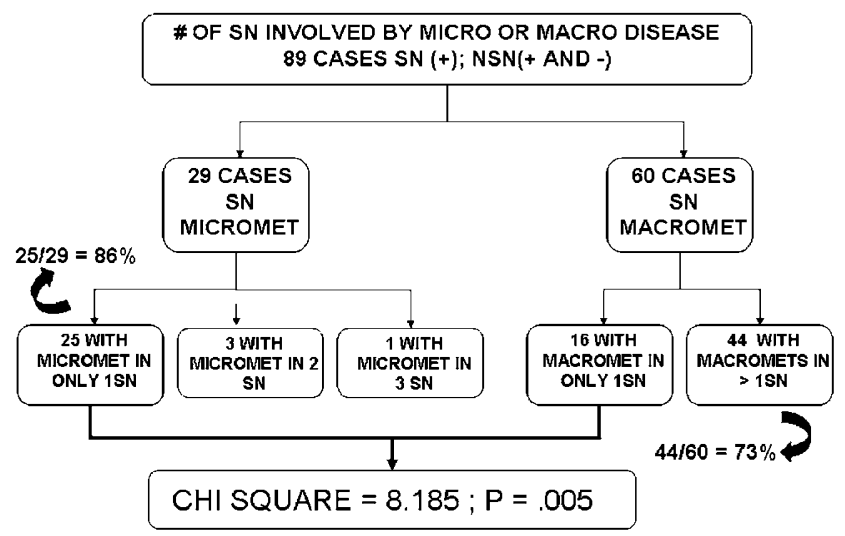

Figure 4 Nonsentinel node positivity (micro- or macrometastases) remains significantly lower at intraoperative consult in patients with sentinel node micrometastasis, than in patients with sentinel node macrometastatic disease (5 vs $64 \%: P=0.012$ ).

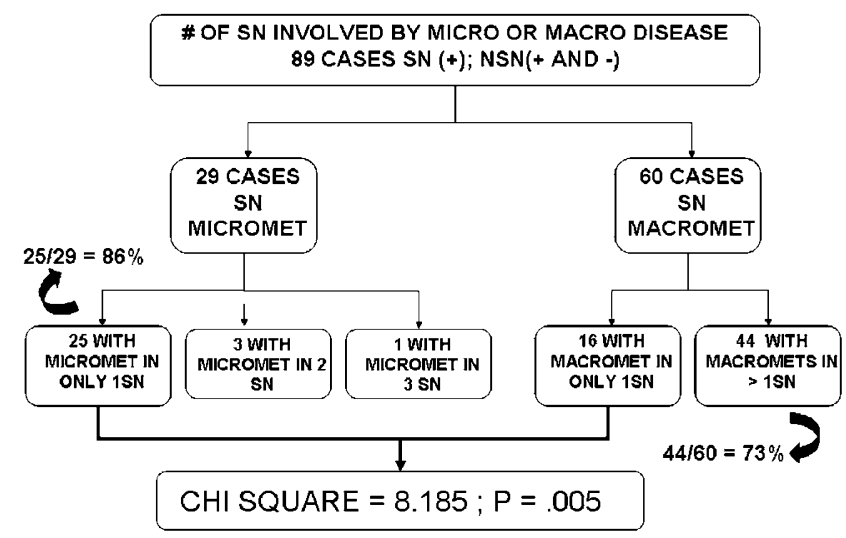

Figure 5 Patients with sentinel node micrometastatic disease are more likely to have only one sentinel node involved by tumor, in contrast to patients with sentinel node macrometastatic disease ( $86 \%$ compared to $27 \%$ ). 
cytologic preparations alone (Figure $7 \mathrm{a}$ and b). Figure $7 \mathrm{c}$ and $\mathrm{d}$ show examples of cases in which isolated tumor cells detected by cytokeratin stains were classified as metastatic disease with subse-

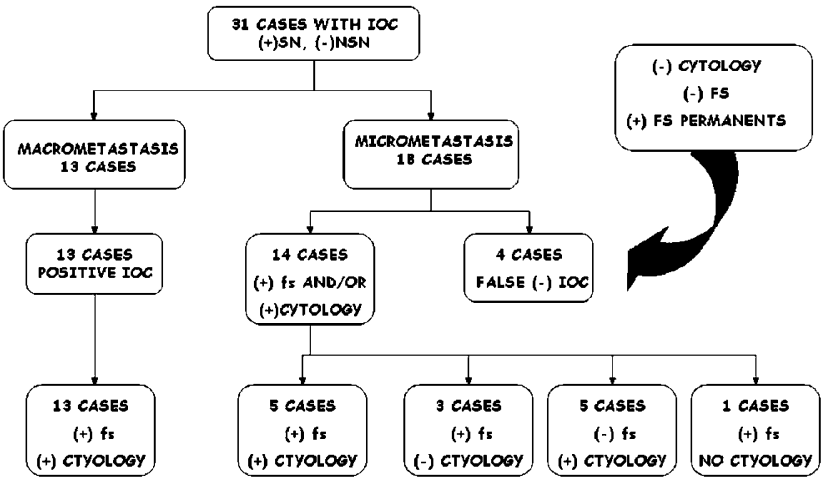

Figure 6 Cases with sentinel node macrometastasis had positive frozen section and cytology (touch-prep and/or scrape-prep) evaluation. While in patients with micrometastatic disease, there was no consistent diagnostic method (frozen section or cytology) to detect metastasis. quent complete axillary dissection (these cases were not included in the presented data).

\section{Discussion}

We address the rationale of proceeding with a complete axillary node dissection as part of a single surgical procedure, based solely on sentinel node status at intraoperative consult. This rationale is relevant as the clinical significance and morphologic definition of micrometastatic disease in breast carcinoma are currently under scrutiny. ${ }^{9,12,25,26}$ Clinicians should be aware of the diagnostic limitations of the frozen section, not only in terms of sensitivity, but also in terms of accurate representation of metastatic tumor size. Surgical pathologists should also understand the clinical implication of a complete axillary dissection based on a positive sentinel node intraoperative consult evidenced by single or limited clusters of malignant cells present only in cytologic preparations. In those cases, the cells in question may very well represent
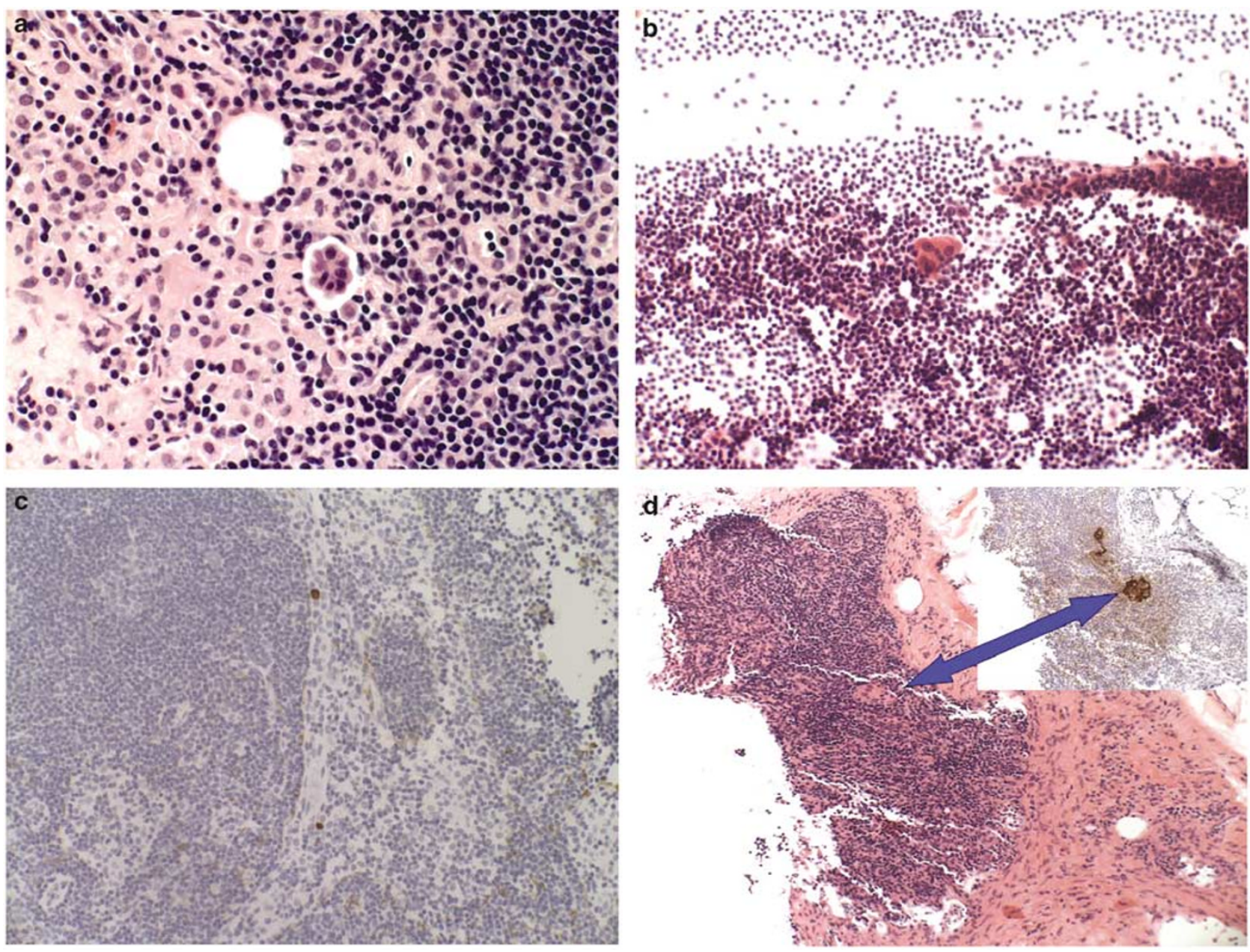

Figure 7 (a) $\times 20 \mathrm{H} \& \mathrm{E}$ section of tumor deposit in sentinel node measuring $<1 \mathrm{~mm}$. (b) $\times 20$ H\&E cytology preparation showing tumor cells in a sentinel node measuring $<1 \mathrm{~mm}$. (c) $\times 10$ Cytokeratin-stained section from sentinel node showing single tumor cells. (d) $\times 10$ $\mathrm{H} \& \mathrm{E}$ and cytokerain stains of tumor deposits $<0.02 \mathrm{~mm}$ in sentinel node. 
subcapsular tumoral deposits, benign transport, benign inclusions, etc. ${ }^{27,28}$ and may not necessarily be true metastatic deposits (Figure 7a-d).

The size of sentinel node metastases, presence of extranodal extension in sentinel node, tumor size $>2 \mathrm{~cm}$, more than one positive sentinel node, and lymphvascular invasion in the primary tumor have been identified as potential clinicopathologic features that could predict or increase the likelihood of nonsentinel node metastasis. ${ }^{29,30}$ Degnim et al performed a meta-analysis of 15 previous studies in which it was shown that the presence of any one of these characteristics would increase the likelihood of nonsentinel node metastasis by at least twofold, and that any subgroup with just one of these characteristics present had a $>10 \%$ chance of nonsentinel node metastasis. While in this series, tumor size (T1 vs T2 or greater), size of sentinel node metastasis (macro- vs micrometastasis), tumor grade, presence of lymphvascular invasion, and extranodal extension of sentinel node metastases were all found to significantly increase the chance for metastatic disease (either micro or macrometastatic) in sentinel and nonsentinel nodes as expected, they did not necessarily discriminate between patients with micro- vs macrometastatic nodal disease. The only variable found to significantly differ between patients with micro- VS macrometastasis was the presence of metastatic extracapsular nodal extension, and even so, this variable was not uniformly present in all patients with macrometastatic positive nodes (either sentinel or nonsentinel) nor was it restricted to large, high-grade tumors (Table 1). Many retrospective analyses trying to identify a group of breast cancer patients in whom axillary dissection could potentially be avoided ${ }^{19,20,31}$ have been attempted. This study suggests that complete axillary dissections could be avoided in patients with grade I tumors, tumors of special histologic type, and those $1 \mathrm{~cm}$ or less, even with sentinel node micrometastatic disease. Divergent results between studies may be the result of patient selection criteria and differences in the methods used to identify, sample, or process sentinel nodes, among other factors.

The prognostic significance of axillary nodal status in breast cancer patients is not only determined by the size of metastatic disease per se, but more importantly, by the number of nodes involved. In this series, the chances of identifying more than one positive node after a diagnosis of sentinel node micrometastasis was significantly lower than when a sentinel node was found to contain macrometastatic disease. Furthermore, our data suggest that regardless of primary tumor size and grade, lymphvascular invasion and extracapsular nodal metastatic extension, the presence of sentinel node micrometastases at intraoperative consult or on permanent histology does not guarantee additional metastatic disease in other sentinel or nonsentinel nodes. Patients with single node micrometastasis appear to represent a different subset of breast cancer patients in which the prognostic significance of their axillary node status is not yet fully understood. Furthermore, their nodal status may or may not directly impact their treatment options in terms of chemotherapy and further axillary surgical treatment. To universally proceed with complete axillary dissection immediately following a positive intraoperative consult or permanent histology diagnosis of sentinel node micrometastasis, appears to defeat the purpose of sentinel node mapping. As in the majority of these patients, the likelihood of other positive nodes is very low.

To avoid unnecessary surgical procedures, we propose to forego performing immediate complete axillary dissection in those patients who have an intraoperative consult sentinel node diagnosis of micrometastasis on frozen section or in the presence of limited malignant cytologic material (such as single cells, few clustered cells, etc.) not present in the corresponding frozen section. Our data suggest that complete axillary dissection may not be needed in cases where micrometastatic disease is found in a sentinel node. The risk of complete axillary dissection should be carefully weighed against the benefit of undertaking this procedure in such cases.

\section{References}

1 Bass SS, Cox CE, Ku NN, et al. The role of sentinel lymph node biopsy in breast cancer. J Am Coll Surg 1999;189:183-194.

2 Hill AD, Tran KN, Akhurst T, et al. Lessons learned from 500 cases of lymphatic mapping for breast cancer. Ann Surg 1999;229:528-535.

3 Veronesi U, Paganelli G, Viale G, et al. Sentinel lymph node biopsy and axillary dissection in breast cancer: results in a large series. J Natl Cancer Inst 1999;91: 368-373.

4 Ratanawichitrasin A, Biscotti CV, Levy L, et al. Touch imprint cytological analysis of sentinel lymph nodes for detecting axillary metastases in patients with breast cancer. Br J Surg 1999;86:1346-1348.

5 Karamlou T, Johnson NM, Chan B, et al. Accuracy of intraoperative touch imprint cytologic analysis of sentinel lymph nodes in Breast Cancer. Am J Surg 2003;185:425-428.

6 Shiver SA, Creager AJ, Geisinger K, et al. Intraoperative analysis of sentinel lymph nodes by imprint cytology for cancer of the breast. Am J Surg 2002;184: 424-427.

7 Sawada T, Sakurada M, Hasegawa Y, et al. Intraoperative evaluation of axillary lymph nodes for micrometastases using immunohistochemistry-preliminary study. Rinsho Byori 2003;51:522-527.

8 Winchester DJ, Sener SF, Winchester DP, et al. Sentinel lymphadenectomy for breast cancer: experience with 180 consecutive patients: efficacy of filtered technetium $99 \mathrm{~m}$ sulphur colloid with overnight migration time. J Am Coll Surg 1999;188:597-603.

9 Weaver DL. Sentinel lymph nodes and breast carcinoma: which micrometastases are clinically significant? Am J Surg Pathol 2003;27:842-845. 
10 Liang WC, Sickle-Santanello BJ, Nims TA. Is a completion axillary dissection indicated for micrometastases in the sentinel lymph node? Am J Surg 2001;182:365-368.

11 Noguchi M. Therapeutic relevance of breast cancer micrometastases in sentinel lymph nodes. Br J Surg 2002;89:1505-1515.

12 Carcoforo P, Berossi L, Basaglia K, et al. Prognostic and therapeutic impact of sentinel node micrometastasis in patients with invasive breast cancer. Tumori 2002; 88:S4-S5.

13 Viale G, Maiorano E, Mazzarol G, et al. Histologic detection and clinical implications of micrometastases in axillary sentinel lymph nodes for patients with breast carcinoma. Cancer 2001;92:1378-1384.

14 Bochner MA, Farshid G, Dodd TJ, et al. Intraoperative imprint cytologic assessment of the sentinel node for early breast cancer. World J Surg 2003;27: 430-432.

15 Baitchev G, Gortchev G, Todorova A. Intraoperative sentinel lymph node examination by imprint cytology during breast surgery. Curr Med Res Opin 2002; 18:185-187.

16 Mullenix PS, Carter PL, Martin MJ, et al. Predictive value of intraoperative touch preparation analysis of sentinal lymph nodes for axillary metastasis in breast cancer. Am J Surg 2003;185:420-424.

17 Nos C, Freneaux P, Louis-Sylvestre C, et al. Macroscopic quality control improves the reliability of blue dye-only sentinel lymph node biopsy in breast cancer. Ann Surg Oncol 2003;10:525-530.

18 Motomura K, Inaji H, Kasugai T, et al. Intraoperative sentinel lymph node examination by imprint cytology and frozen sectioning during breast surgery. Br J Surg 2000;87:597-601.

19 Reynolds C, Mick R, Donohue JH, et al. Sentinel lymph node biopsy with metastasis: can axillary dissection be avoided in some patients with breast cancer? J Clin Oncol 1999;17:1720-1726.

20 Chu KU, Turner RR, Hansen NM, et al. Do all patients with sentinel node metastasis from breast carcinoma need complete axillary node dissection? Ann Surg 1999;229:536-541.
21 Samayoa LM, Witzke D, Sloan D, et al. Defining sentinel lymph nodes in breast carcinoma. Mod Pathol 2001;14:189.

22 Greene FL, Page DL, Fleming ID, et al (eds). AJCC Cancer Staging Manual, 6th edn. Springer: New York, 2002, pp 221-236.

23 Singletary SE, Greene FL, Sobin LH. Classification of isolated tumor cells: clarification of the 6th edition of the American Joint Committee on Cancer Staging Manuel. Cancer 2003;98:2740-2741.

24 Elston CW. Grading of invasive carcinoma of the breast. In: Page DL, Anderson TJ (eds). Diagnostic Histopathology of the Breast. Churchill Livingstone: New York, 1987, pp 300-311.

25 Cox CE, Yeatman T, Salud CJ, et al. Significance of sentinel node micrometastasis. Cancer Control 1999;6: 601-605.

26 den Bakker MA, Weezenberg A, de Kanter AY, et al. Non-sentinel lymph node involvement in patients with breast cancer and sentinel node micrometastasis; too early to abandon axillary clearance. J Clin Pathol 2002;55:932-935.

27 Moore KH, Thaler HT, Tan LK, et al. Immunohistochemically detected tumor cells in the sentinel lymph nodes of patients with breast carcinoma: biologic metastasis or procedural artifact? Cancer 2004;100: 929-934.

28 Carter BA, Jensen RA, Simpson JF, et al. Benign transport of breast epithelium into axillary lymph nodes after biopsy. Am J Clin Pathol 2000;113:259-265.

29 Weiser MR, Montgomery LL, Tan LK, et al. Lymphovascular invasion enhances the prediction of nonsentinel node metastases in breast cancer patients with positive sentinel nodes. Ann Surg Oncol 2001;8: 145-149.

30 Degnim AC, Griffith KA, Sabel MS, et al. Clinicopathologic features of metastasis in nonsentinel lymph nodes of breast carcinoma patients. Cancer 2003;98: 2307-2315.

31 Abdeessalam SF, Zervos EE, Prasad M, et al. Predictors of positive axillary lymph nodes after sentinel lymph node biopsy in breast cancer. Am J Surg 2001;182: $316-320$. 